Research Article

\title{
Identification of Functional Groups in Different Parts of an Invasive Alien Weed
} Hyptis suaveolens (L.) Poit

\author{
Maneesh Kumar Lomas, Arvind Kumar, Rup Narayan* \\ Ecology Research Lab, Department of Botany, Chaudhary Charan Singh University, Meerut-250004, India. \\ *Corresponding author's E-mail: rupnarayan2001@gmail.com
}

Received: 20-10-2021; Revised: 18-12-2021; Accepted: 26-12-2021; Published on: 15-01-2022.

\begin{abstract}
Plants are rich in different bioactive compounds which vary in their structure and properties. The present study on the invasive weed Hyptis suaveolens aimed to identify the functional groups (FTIR spectroscopic) in its different plant components viz leaf, stem, root, calyx and seeds. The results shows various characteristic peak values with different functional groups in air-dried powered samples of the plant parts. In FTIR analysis, forty one functional groups of different classes of compounds were identified. However, the highest number of functional groups (39) were recorded in reproductive component alone (calyx 35 and seed 25 separately), followed by stem (32), root (31), and leaf (29). The results revealed further investigation to explore its utility for medicinal uses.
\end{abstract}

Keywords: Hyptis suaveolens, FT-IR, Functional groups, invasive.

QUICK RESPONSE CODE $\rightarrow$

DOI:

10.47583/ijpsrr.2022.v72i01.017

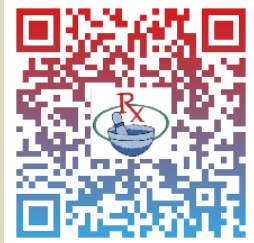

DOI link: http://dx.doi.org/10.47583/ijpsrr.2022.v72i01.017

\section{INTRODUCTION}

A large spectrum of biochemical substances is synthesized by plants via both primary and secondary metabolic processes that impact plant's defence, signalling, interference with enzymatic and hormonal activities, and disease-cure etc. Thus, it is essential to validate plants especially those of medicinal importance for their phytochemical profile using different sophisticated techniques. Of the various techniques, FT-IR spectroscopic analysis is considered an effective powerful technique for investigation of phytochemical groups and characterizing chemical bonds present in biological samples ${ }^{1-3}$.

Hyptis suaveolens (L.) Poit. (family Lamiaceae), native of tropical America, commonly known as Pignut or Bushmint, is considered as a highly noxious invasive weed, reported across several natural ecosystems in tropics and subtropics ${ }^{4,5}$. This weed in India has been reported from Vindhyan region, North-East India, Deccan Peninsula and Andaman and Nicobar Islands ${ }^{6}$ and Telangana region ${ }^{7}$. It is basically a pan-tropic, annual and aromatic herb that grows luxuriantly in the months of July-November, along the railway tracks, roadsides and wastelands ${ }^{8}$. This dicotyledonous plant is reported to be of immense medicinal value as it contains essential oils, alkaloids, flavonoids, phenols, saponins, terpenes and sterols ${ }^{9}$ with antiplasmodial ${ }^{10}$, anticonvulsant, antirheumatic ${ }^{11}$, antiinflammatory, antiulcerogenic, carminative and lactagogue properties. Several workers reported its use in various treatments like uterine affections, parasitical cutaneous diseases and gall bladder infections ${ }^{12-14}$.

The major aim of the present study on Hyptis suaveolens was to investigate the main functional components of different phytochemical groups present in the different parts of this invasive weed.

\section{MATERIALS AND METHODS}

\section{Plant Species}

Hyptis suaveolens: It is a rampant, annual herbaceous weed. Stem of this plant is well-branched, woody, extremely hairy, cubic shape and green or reddish-green in nature, extending up to normally 1-1.5 metre in length. Hairy petiolate leaves are simple, opposite, decussate and ovate or slightly cordate in shape. 2-5 flowers appear in a small cyme which is light purple or pinkish in colour. The calyx is $5 \mathrm{~mm}$ long and campanulate. The fruit held within the calyx divides into two nutlets, each of which contains a single seed which is about 1.2-2 mm long, dark-brown in colour and slightly notched at the end.

\section{Study Area}

The present study was carried out at Sanjay Van (28 $56^{\prime} 48.07^{\prime \prime} \mathrm{N}$ lat. and $77^{\circ} 40^{\prime} 26.15^{\prime \prime} \mathrm{E}$ long.) in Meerut, located in western Uttar Pradesh, India. Highly urbanised city of Meerut is well connected (Road and Railways) with industrialised areas of Ghaziabad, Noida and Hapur in Uttar Pradesh, Roorkee in Uttarakhand and the National Capital Region of Delhi. Several annual and perennial exotic weeds are abundant here. Of these, $H$. suaveolens weed has assumed considerable significance on account of its rapid colonizability and ability to occupy new environments impacting the soils and diversity structure of plant communities in the vicinity. 
The climate of the study area is semi-arid having three seasons- rainy (Jul-Sep), winter (Nov-Feb) and summer (Mar-Jun).

\section{Functional Group Analysis}

Ten randomly selected mature plant individuals in seedproducing stage with proper attachment of roots were collected for the study of their functional groups. The leaves, stem, calyx and root components of the plant were separated and washed thoroughly in tap water to remove dust but seeds were not cleaned by water as the seeds produce mucilage after getting in contact with water ${ }^{4}$. So, the soil particles on the seed were cleaned by cotton. All plant-organ samples were air-dried at room temperature on clean blotting sheets and after complete drying, their powdered samples prepared through grinder were stored in air-tight poly bags for further FTIR (Fourier Transform Infrared) Spectroscopic analysis. All spectra were recorded on Agilent FTIR Spectrometer (ATR module of cary 630 FTIR, Agilent Technologies). The powdered samples of the weed plant parts in small amounts were placed directly on the germination piece of the infrared spectrometer with constant applied, and data of infrared absorbance were collected over the wave number that ranged from 600 $4000 \mathrm{~cm}^{-1}$ with resolution of $2 \mathrm{~cm}^{-1}$. The reference spectra were acquired from the cleaned blank crystal prior to the presentation of each sample replicate. The FTIR spectrum of all samples was analysed on the basis of peak values in the region of infrared radiation.

\section{RESULTS AND DISCUSSION}

Various absorption peak values of different plant organs were recorded in this study (Fig. 1 A-E) which showed different known functional groups. However, one peak value 1890.342 was found in calyx component that denoted unknown functional groups. Correspondingly, forty one functional groups of different classes of compounds were identified across five different plant components (leaf, stem, root, calyx and seed) of the investigated invasive weed Hyptis (Table 1). Out of these 41 functional groups, only 16 groups were common in all five plant parts. These were alcohol, aldehydes, alkanes, amides, amines, anhydrides, aromatic $\mathrm{C}-\mathrm{H}$, aromatic ring, carboxylate salt, carboxylic acid, C-C aliphatic chain, ester, ethers, fluoride, phenol and sulfonic acid (Table 1). Eleven functional groups (alkene, aromatic azo, $\mathrm{C}=\mathrm{S}$, isonitrile, Si$\mathrm{H}$, Si-O-C, Si-O-Si, sulfates, sulfonamides, sulfones and sulfonyl chlorides) were recorded common in four plant parts. Amongst these, six functional groups isonitrile, $\mathrm{Si}-\mathrm{H}$, sulfates, sulfonamides, sulfones and sulfonyl chlorides were present in leaf, stem, calyx and root; four functional groups (Aromatic azo, $\mathrm{C}=\mathrm{S}$, Si-O-C and $\mathrm{Si}-\mathrm{O}-\mathrm{Si}$ ) recorded in other plant parts were absent in leaf. Of these eleven functional groups stem lacked only alkene.

Four functional groups viz. alkyne, azide, hetero-ring and Nitro were found common in three plant organs. All these four functional groups were found in stem and of these four, only one functional group was recorded in stem (hetero-ring) and seed (nitro) component of the plant. Six functional groups comprising of allenes, isocyanate, isothiocyanate, ketenes, lactone and thiocyanate occurred common in two plant components only. Of these, the leaf and calyx possessed four common functional groups which also showed strong intensity (allenes, isocyanate, isothiocyanate and ketenes). They were, however, completely absent in other three plant components (stem, seed and root). Lactone was recorded only in stem and seed and thiocyanate in stem and root only. Four functional groups i.e. aliphatic azo, $\mathrm{C}=\mathrm{N}$, ketones and $\mathrm{P}-\mathrm{H}$ ) were present in only one part of the plant. While ketone was recorded in stem only, aliphatic azo and $\mathrm{C}=\mathrm{N}$ were recorded in seed and $\mathrm{P}-\mathrm{H}$ functional group only in calyx plant components.

Highest number of functional groups (35) was found in calyx component, followed by stem (32), root (31), leaf (29) and seed (25). Considering calyx and seed under reproductive part component, a total of thirty-nine (39) functional groups were recorded in this segment of plant. The forty one functional groups recorded in this present study differed in their intensity across plant segments (Table 1). Strong intensity was exhibited by eighteen functional groups, which included alkanes, anhydrides, aromatic $\mathrm{C}-\mathrm{H}$, ethers and fluoride found in all five plant components in this study. Six functional groups viz. aromatic azo, $\mathrm{C}=\mathrm{S}$, sulfates, sulfonamides, sulfones and sulfonyl chlorides were found common in four plant organs with strong intensity. Amongst these, four functional groups sulfates, sulfonamides, sulfones and sulfonyl chlorides were present in leaf, stem, calyx and root; two functional groups (aromatic azo and $\mathrm{C}=\mathrm{S}$ ) recorded in other plant parts were absent in leaf. Hetero-ring was found common in three plant organs (leaf, stem and calyx) with strong intensity. Allenes, isocyanate, isothiocyanate and ketenes found only in leaf and calyx also showed strong intensity. Ketone found only in single organ leaf and $\mathrm{C}=\mathrm{N}$ in seed also exhibited strong intensity. Medium intensity was recorded for 10 functional groups and weak intensity in only 5 functional groups, strong to medium intensity was exhibited by 7 functional groups which included alcohol, amides, amines, aromatic ring, carboxylic acid and esters found common in every part of the plant components, and nitro found in stem, seed and root. Out of 41 functional groups which were recorded in the plant components in this study, only aldehyde group showed strong and weak intensity in different plant organs on the basis of absorption peak value.

FTIR spectrum is often used to confirm the presence of functional constituents in the given plant samples, to identify and evaluate the qualities of medicinal materials ${ }^{17}$. The results of the present study revealed the presences of various functional groups in different plant components of the investigated invasive weed. 
Table 1: FTIR frequency range, intensity and functional groups of different plant components of noxious weed Hyptis suaveolens (A: Leaf, B: Stem, C: Calyx, D: Seed and E: Root)

\begin{tabular}{|c|c|c|c|c|c|c|c|c|c|}
\hline \multirow{2}{*}{ S.N. } & \multirow{2}{*}{ Functional group } & \multicolumn{5}{|c|}{ Hyptis suaveolens parts } & \multirow{2}{*}{ Frequency range $\left(\mathrm{cm}^{-1}\right)$} & \multirow{2}{*}{ Intensity } & \multirow{2}{*}{ References } \\
\hline & & A & B & C & D & $\mathbf{E}$ & & & \\
\hline 1 & Alcohol & + & + & + & + & + & $3200-3400,1000-1300$ & $M, S$ & 15 \\
\hline 2 & Aldehydes & + & + & + & + & + & $2800-2900,1720-1740$ & $\mathrm{~W}, \mathrm{~S}$ & 15 \\
\hline 3 & Alkanes & + & + & + & + & + & $2850-3000$ & S & 15 \\
\hline 4 & Amides & + & + & + & + & + & $3100-3500,1550-1640$ & $M, S$ & 15 \\
\hline 5 & Amines & + & + & + & + & + & $3100-3500,1550-1640,1000-1350$ & $\mathrm{M}, \mathrm{S}$ & 15 \\
\hline 6 & Anhydrides & + & + & + & + & + & $1000-1300$ & $\mathrm{~s}$ & 15 \\
\hline 7 & Aromatic $\mathrm{C}-\mathrm{H}$ & + & + & + & + & + & $2870-3100$ & $\mathrm{~S}$ & 16 \\
\hline 8 & Aromatic ring & + & + & + & + & + & $1550-1610,990-1100,1450-1550$ & $S, M$ & 16 \\
\hline 9 & Carboxylate salt & + & + & + & + & + & $1315-1435$ & M & 16 \\
\hline 10 & Carboxylic acid & + & + & + & + & + & $2400-3400,1700-1725$ & $M, S$ & 15 \\
\hline 11 & C-C Aliphatic chain & + & + & + & + & + & $630-1250$ & M & 16 \\
\hline 12 & Esters & + & + & + & + & + & $1000-1300,1730-1750$ & $S, M$ & 15 \\
\hline 13 & Ethers & + & + & + & + & + & $1000-1300$ & $\mathrm{~S}$ & 15 \\
\hline 14 & Fluoride & + & + & + & + & + & $1000-1400$ & $\mathrm{~s}$ & 15 \\
\hline 15 & Phenol & + & + & + & + & + & $3200-3400$ & M & 15 \\
\hline 16 & Sulfonic acid & + & + & + & + & + & $1145-1240$ & w & 16 \\
\hline 17 & Alkene & + & - & + & + & + & $1600-1680$ & M & 15 \\
\hline 18 & Aromatic azo & - & + & + & + & + & $1365-1450$ & S & 16 \\
\hline 19 & $\mathrm{C}=\mathrm{S}$ & - & + & + & + & + & $1020-1225$ & S & 16 \\
\hline 20 & Isonitrile & + & + & + & - & + & $2090-2170$ & M & 16 \\
\hline 21 & $\mathrm{Si}-\mathrm{H}$ & + & + & + & - & + & $2080-2150$ & M & 16 \\
\hline 22 & $\mathrm{Si}-\mathrm{O}-\mathrm{C}$ & - & + & + & + & + & 1010-1095 & w & 16 \\
\hline 23 & $\mathrm{Si}-\mathrm{O}-\mathrm{Si}$ & - & + & + & + & + & $1010-1095,1120-1190$ & w & 16 \\
\hline 24 & Sulfates & + & + & + & - & + & $1300-1375$ & s & 15 \\
\hline 25 & Sulfonamides & + & + & + & - & + & $1300-1375$ & $\mathrm{~s}$ & 15 \\
\hline 26 & Sulfones & + & + & + & - & + & $1300-1375$ & $\mathrm{~s}$ & 15 \\
\hline 27 & Sulfonyl chlorides & + & + & + & - & + & $1300-1375$ & S & 15 \\
\hline 28 & Alkyne & - & + & + & - & + & $2100-2250$ & M & 15 \\
\hline 29 & Azide & - & + & + & - & + & $2110-2160$ & M & 16 \\
\hline 30 & Heteroring & + & + & + & - & - & $1550-1610$ & S & 16 \\
\hline 31 & Nitro & - & + & - & + & + & $1320-1350,1535-1600$ & $S, M$ & 16 \\
\hline 32 & Allenes & + & - & + & - & - & $1940-2270$ & S & 15 \\
\hline 33 & Isocyanates & + & - & + & - & - & $1940-2270$ & S & 15 \\
\hline 34 & Isothiocynate & + & - & + & - & - & $1940-2270$ & S & 15 \\
\hline 35 & Ketenes & + & - & + & - & - & $1940-2270$ & $\mathrm{~S}$ & 15 \\
\hline 36 & Lactone & - & + & - & + & - & $1735-1790$ & $M$ & 16 \\
\hline 37 & Thiocynate & - & + & - & - & + & $2100-2170$ & w & 16 \\
\hline 38 & Aliphatic azo & - & - & - & + & - & $1540-1590$ & $M$ & 16 \\
\hline 39 & $\mathrm{C}=\mathrm{N}$ & - & - & - & + & - & $1630-1665$ & S & 16 \\
\hline 40 & Ketone & + & - & - & - & - & $1705-1725$ & S & 15 \\
\hline 41 & $\mathrm{P}-\mathrm{H}$ & - & - & + & - & - & $2290-2420$ & w & 16 \\
\hline
\end{tabular}


Figure 1: FTIR spectrum of different plant components (A-E) of exotic weed Hyptis suaveolens (A- Leaf; B-Stem; C-Calyx; DSeed and E-Root)
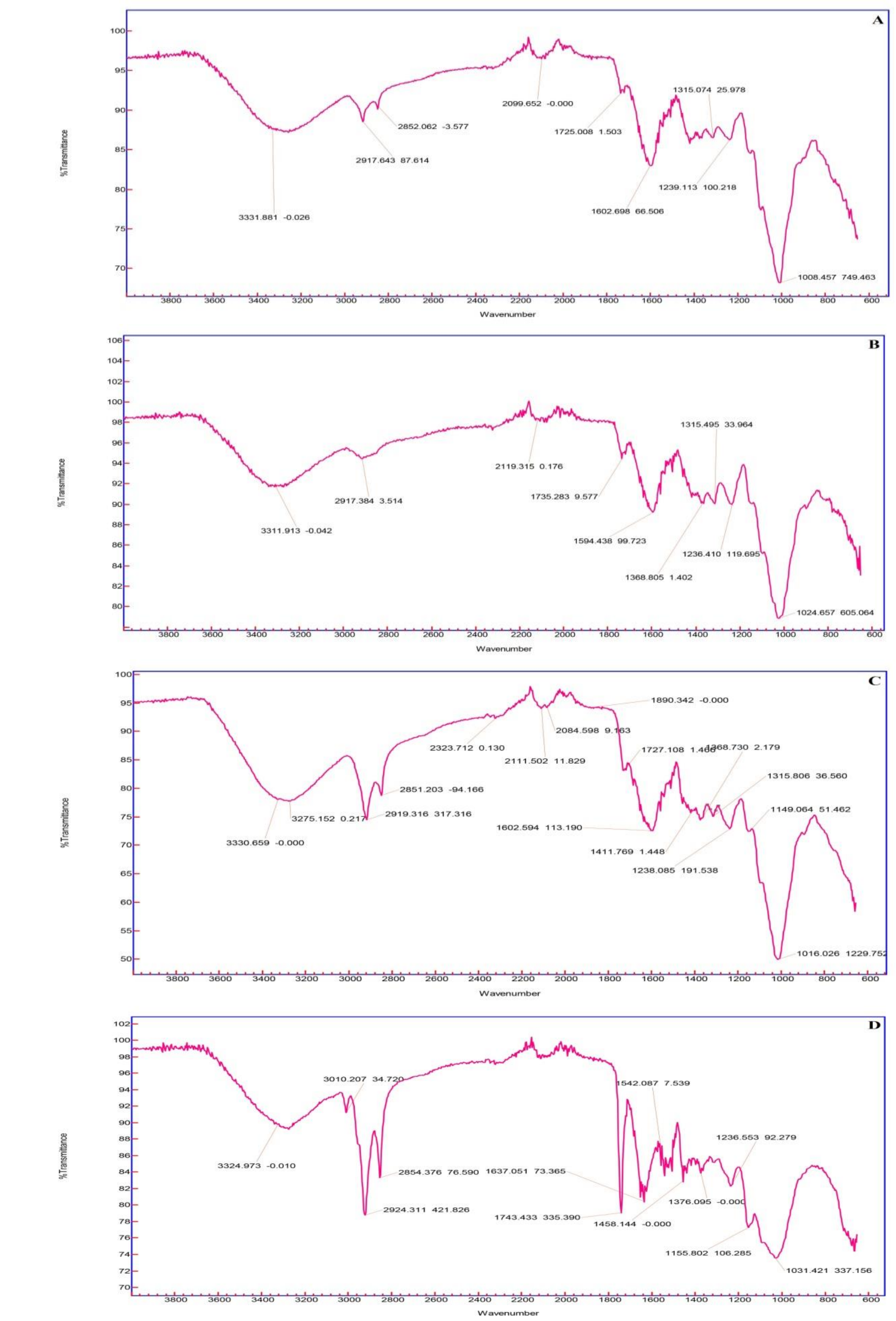


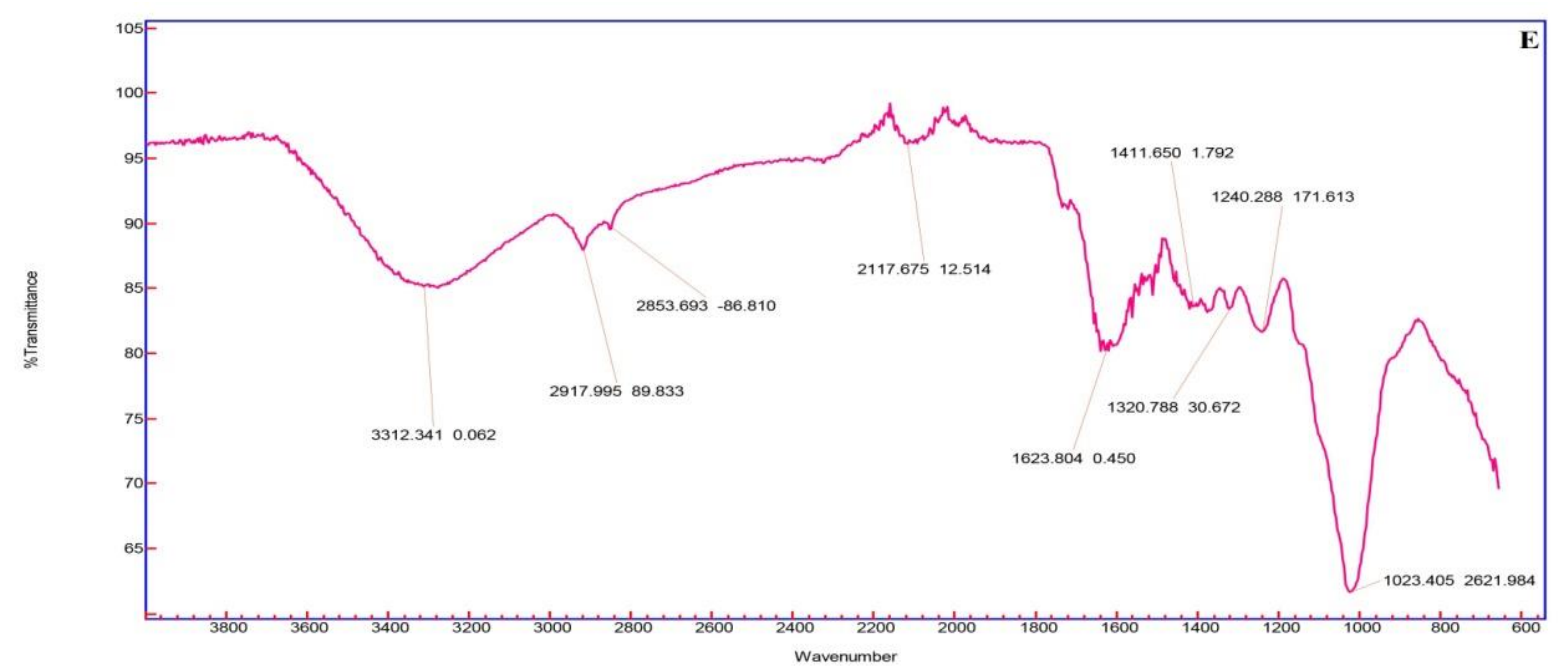

Hyptis possessed functional groups of active compound like alkanes, aromatic, alkene, alcohols, ketones, carboxylic acid etc. which were also reported in this weed by Kumar and Thampi ${ }^{18}$ and Malathi et al. ${ }^{19}$ in ethanol, aqueous, acetone and methanol extracts of leaf and seed of this weed by FTIR analysis. FTIR screening of functional groups exhibiting the presence of carboxylic acids, esters, ethers, amines, amides, alcohol, phenols, sulfonic acid etc. indicated possibility of various medicinal properties in this exotic weed. Phenolics are aromatic benzene ring compounds that are commonly produced in plants under stress conditions. It also plays a vital role in plant lignin biosynthesis and development. So these plants may be considered a good source of antimicrobial agents ${ }^{20}$. Presence of alkene in Hyptis also indicated tendency to possession of various medicinal properties in this plant species. Carboxylic acids, also found in it, are biologically very important in the formation of fat in the body ${ }^{18}$.

Presence of highest number of functional groups (39) in reproductive organs (calyx-35 and seed-25) clearly indicated an important role and plausible potential of reproductive plant component in the investigated of $H$. suaveolens for medicinal purposes. However, this aspect pertaining to medicinal application needs further investigation.

\section{CONCLUSION}

The present study revealed presence of 41 functional groups in different parts of Hyptis suaveolens, of which the largest number of functional groups were recorded in the reproductive component, indicating immense medicinal potential too in this invasive weed, which has implication for its pharmaceutical uses. Further advanced spectroscopic studies need to be undertaken to elucidate the structure and identification of active principles present in this plant.

Acknowledgments: We acknowledge our sincere thanks to the University Grants Commission, New Delhi, for providing financial support in the form of JRF/SRF to the first author.

\section{REFERENCES}

1. Annette N, Lukas K, Andrea K, Hansjoerg H and Hartwig S, Discrimination of Solanaceae taxa and quantification of scopolamine and hyoscyamine by ATR-FTIR Spectroscopy. Planta Medica, 2014; 80(15): 1315-1320.

2. Anil Kumar VS, Sunila AV and Murugan K, Micromorphological and FTIR spectral analysis of Solanum trilobatum L. (Solanaceae)- a medicinally valued thorny creeper from South India, International Journal of Advance Reserach, 2016; 4(1): 1249-1257.

3. Charushila D and Swaroopa D, FTIR spectroscopic screening of phytochemicals of two medicinally important species of Solanum used in preparation of dashmula formulation, International Journal of Pharmaceutical Science Review and Research, 2016; 36(2): 112-120.

4. Raizada $P$, Ecological and vegetative characteristics of a potent invader, Hyptis suaveolens Poit. From India. Lyonia, 2006; 11(2):115-120.

5. Padalia H, Srivastava $V$ and Kushwaha SPS, Modelling potential invasion range of alien invasive species, Hyptis suaveolens (L.) Poit. In India: comparison of MaxEnt and GARP. Ecological Informatics, 2014; 22: 36-43.

6. Sharma H, Batish DR, Singh HP, Jaryana J and Kohli RK, The impact of invasive Hyptis suaveolens on the floristic composition of the periurban ecosystems of Chandigarh, northwest India. Flora, 2017; 233: 156-162.

7. Suthari S, Kandagatla R, Geetha S, Ragan A \& Raju VS, Intrusion of devil weed Chromolaena odorata, an exotic invasive, into Kinnerasani and Eturnagaram wildlife Sanctuaries, Telangana, India, Journal of Threatened Taxa, 2016; 8(2): 8538-8540.

8. Mudgal V, Khanna KK and Hazra PK, Flora of Madhya Pradesh II. (Botanical Survey of India), 1997; 403.

9. Ziegler HL, Jensen TH, Christensen J, Staerk D and Hagestr $\mathrm{H}$, Possible artefacts in the in vitro determination of antimalarial activity of natural products that incorporate into lipid bilayer: Apparent antiplasmodial activity of dehydroabietinol, a constituent of Hyptis suaveolens, Planta Medica, 2002; 68(6): 547-549.

10. Chukwujekwu JC, Smith P, Coombes PH, Mulholland DA and Staden JV, Antiplasmodial diterpenoid from the leaves of 
Hyptis suaveolens, Journal of Ethnopharmacology, 2005; 102(2): 295-297.

11. Akah PA and Nwambie Al, Nigerian plants with anticonvulsant properties. Fitoterapia, 1993; 64: 42-44.

12. Ahmed M, Scora RW and Ting IP, Composition of leaf oil of Hyptis suaveolens (L.) Poit, Journal of Essential Oil Research, 1994; 6: 571-575.

13. Khare $\mathrm{CP}$, Indian Medicinal Plants: An Illustrated Dictionary (Springer), 2007.

14. Koche D, Shirsat R, Imran S and Bhadange DG, Phytochemical screening of eight traditionally used ethnomedicinal plants from Akola District (MS) India, International Journal of Pharma and Bio Sciences, 2010; 1(4): 253-256.

15. Pavia DL, Lampman GM and Kriz GS, Introduction to spectroscopy (Thomson Learning Inc), 2001, 26.

16. Houghton R, Field Confirmation testing for Suspicious Substances, (CRC Press Tayles and Francis group), 2009, 375.
17. Kumar JK and Prasad AGD, Identification and comparison of biomolecules in medicinal plants of Tephrosia tinctoria and Atylosia albicans by using FTIR, Romanian Journal of Biophysics, 2011; 21(1): 63-71.

18. Kumar NS and Thampi N, Phytochemical screening and characterization of the bioactive compounds from the leaves of Hyptis suaveolens and Spathodea campanulata, Journal of Chemical and Pharmaceutical Research, 2015; 7(7): 840-850.

19. Malathi S, Lahari S, Sahithya P, Ramalingeswar Reddy $P$ and Sai Lakshimi K, Anthelmintic and primer phytochemical examination of dissolvable concentrates of Hyptis Suaveolens from seeds, International Journal of Indigenous Herbs and Drugs, 2019; 4(6): 1-5.

20. Lin $\mathrm{D}$, Xiao $\mathrm{M}$, Zhao J, Li Z, Xing B, Li X, Kong M, Li L, Zhang Q, Liu Y, Chen H, Qin W, Wu H and Chen S, An overview of plant phenolic compounds and their importance in human nutrition and management of Type 2 Diabetes, Molecules, 2016; 21(10): 1374.

Source of Support: The author(s) received no financial support for the research, authorship, and/or publication of this article.

Conflict of Interest: The author(s) declared no potential conflicts of interest with respect to the research, authorship, and/or publication of this article.

For any question relates to this article, please reach us at: globalresearchonline@rediffmail.com New manuscripts for publication can be submitted at: submit@globalresearchonline.net and submit_ijpsrr@rediffmail.com 